\title{
Fatigue in Patients with Multiple Sclerosis in Tehran in 1398
}

\author{
Niloofar Hejazizadeh ${ }^{1}$, Marzieh Pazokian² ${ }^{2}$ Mojtaba $\mathrm{Abdi}^{3}$
}

\begin{abstract}
Background \& Aims: The prevalence of multiple sclerosis (MS) has been on the rise, especially among the youth in Iran. MS is more common in the individuals in their 20s and 40s, while women are also twice as likely to develop MS compared to men. Statistics suggest that there are 2.5 million MS patients worldwide, and this figure has been reported to be 15-30 cases per 100,000 in Iran. According to the Iranian MS Association, approximately 50,000 Iranians have MS, including 9,000 registered cases, and the rate is constantly increasing. Some of the main symptoms of MS are neurological, sensory, motor, and balance disorders, and fatigue is considered to be the most debilitating and common symptom; about one-third of MS patients report fatigue within the first three years of the disease diagnosis. Fatigue is an early symptom in $40 \%$ of MS patients, and $38 \%$ experience fatigue as the first diagnostic symptom. Extensive research has assessed the correlations between MS and various demographic variables, including individual factors (age, gender, education level), familial factors (family history of the disease), social factors (support of social institutions), economic factors (monthly income), emotional factors (family support), and disease-related factors (age at onset, length of hospital stay, medication). The present study aimed to measure fatigue in a large population of MS patients and determine its association with demographic variables.
\end{abstract}

Materials \& Methods: This correlational study was conducted on 296 MS patients referring to the Iranian MS Association in Tehran, Iran during June-August 2019 via computation within a specific period. Fatigue was measured using Krupp fatigue intensity (1989), which has been used in extensive medical research. The minimum and maximum possible scores in this scale are nine and 63, respectively. Scores 9-18 indicate low fatigue, scores 18-45 indicate moderate fatigue, and scores above 45 show high fatigue. In Iran, Shahvaroughi Farahani et al. (2009) have measured the internal consistency of the items in this scale, which has been confirmed at the Cronbach's alpha coefficient of 0.96, showing that the items of this questionnaire measure a concept. In addition, the intraclass correlation-coefficient test has been applied to evaluate the relative reproducibility of the Persian version of the questionnaire, with the value reported to be 0.93 . The inclusion criteria of our study were the ability to communicate, basic literacy, dealing with MS for a minimum of one year, and not being in the acute stage of the disease. Participation was completely voluntary and free. The patients were assured of confidentiality terms regarding their personal information, which was only disclosed to the research team and used for scientific purposes. Data of the patients were collected anonymously, and a code was assigned to each questionnaire to prevent the disclosure of information. Data analysis was performed in SPSS version 16 using independent t-test, ANOVA, Pearson's and Spearman's correlation-coefficient, D'Agostino-Pearson omnibus test, a correlation matrix, and Wilcoxon matched-pairs signed ranks test.

Results: In total, 296 MS patients were enrolled in the study with the mean age of $37.15 \pm 8.85$ years and mean disease duration of $29.95 \pm 22.06$ years. Regarding the treatment costs, 18 patients reported low treatment costs, 74 cases reported moderate costs, while 102 and 63 patients reported high and extremely high treatment costs, respectively. Notably, the variable of medical expenses was correlated with the type of patient insurance $(\mathrm{P}=0.009)$, and the patients with armed forces insurance paid the least expenses for their treatment. The mean exercise duration of the MS patients was $4.34 \pm 2.91$ hours per week, and the mean total fatigue score was 39.18 \pm 14.56 . According to the obtained results, 31 patients $(10.5 \%)$ had low fatigue, 157 patients $(53.3 \%)$ had moderate fatigue, and 108 patients $(36.2 \%)$ had high fatigue. A significant association was also observed

\footnotetext{
1. Student Research Committee, School of Nursing and Midwifery, Shahid Beheshti University of Medical Sciences, Tehran, Iran

2. Medical- Surgical Department, Faculty Member, School of Nursing and Midwifery, Shahid Beheshti University of Medical Sciences, Tehran, Iran (Corresponding author) Tel: 09126851924 Email: pazokian@sbmu.ac.ir

3. Student Research Committee, School of Nursing and Midwifery, Iran University of Medical Sciences, Tehran, Iran
} 
between the involved organs of the patients and fatigue $(\mathrm{P}=0.004)$, so that fatigue was higher in the patients whose four limbs were affected by MS and those with visual impairment in addition to the four affected limbs. In the general classification of disorders in the MS patients (sensory, motor, and sensorimotor disorders), motor disorders were most prevalent $(41.89 \%)$, followed by sensorimotor disorders $(41.71 \%)$ and sensory disturbance $(35.66 \%)$. Furthermore, a significant correlation was observed between the number of hospitalizations due to MS and fatigue $(\mathrm{P}=0.001)$, so that with the increased number of hospitalizations, the patients expressed more fatigue. On average, our participants had three hospitalizations, and a significant association was denoted between marital status and fatigue $(\mathrm{P}=0.042)$. Compared to the single patients, fatigue was more common among the married, divorced, and widowed patients. In addition, monthly income was significantly associated with fatigue $(\mathrm{P}=0.001)$, and the patients with inadequate income expressed more fatigue. Exercise was also significantly correlated with fatigue $(\mathrm{P}=0.018)$, and less fatigue was observed in the patients who had physical exercise.

Conclusion: Considering that fatigue is a common symptom in MS patients, special attention should be paid to the influential factors to identify, eliminate or reduce the factors that are changeable. According to the results, fatigue is one of the most debilitating and common symptoms experienced by MS patients. Therefore, these patients, their families, and the treatment team (especially nurses) must recognize the influential factors in fatigue in order to increase patient awareness and reduce fatigue in these patients. We attempted to identify and report some of the influential factors in fatigue, such as individual and psychological, environmental, and disease-related factors, in the MS patients. It is recommended that proper measures be taken to reduce the debilitative factors and strengthen the factors that reduce fatigue. Moreover, healthcare officials should plan to increase income and create suitable job opportunities for MS patients who experience the limitations caused by the disease. The family members of these patients (especially spouses) could also provide great support, which plays a key role in adapting to the disease, taking measures to reduce fatigue, adherence to the treatment regimen, and reducing the number of hospitalizations in MS patients.

Key words: Multiple sclerosis (MS), Fatigue, Demographic variables

\section{Conflict of Interest: No}

How to Cite: Hejazizadeh N, azokian M, Abdi M. Fatigue in Patients with Multiple Sclerosis in Tehran in 1398. Iran Journal of Nursing. 2020; 33(126):1-15.

Received: 4 Jul 2020

Accepted: 3 Oct 2020 


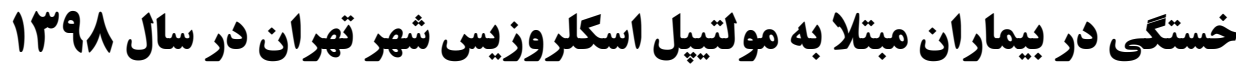

\author{
نيلوفر حجازى زاده'، مرضيه ياز كيان'، مجتبى عبدى"
}

\begin{abstract}
جكيده

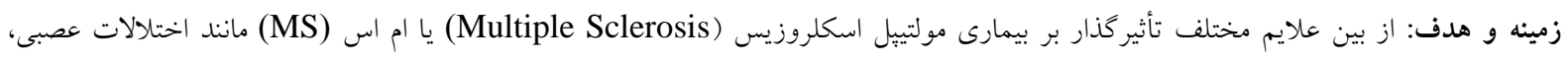

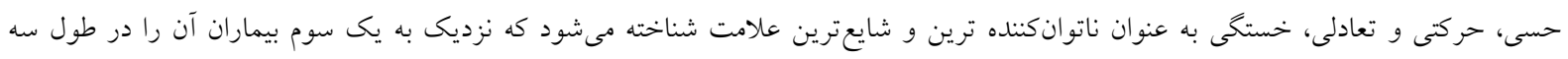

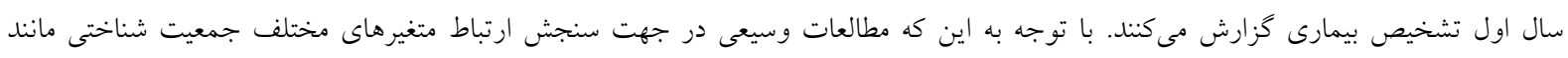

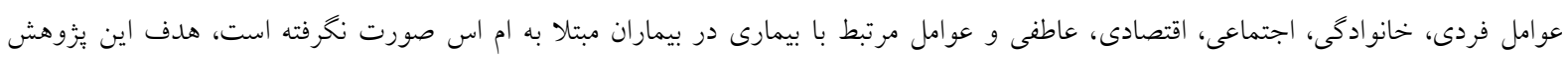

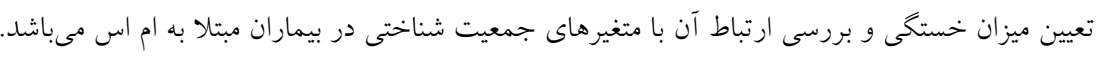

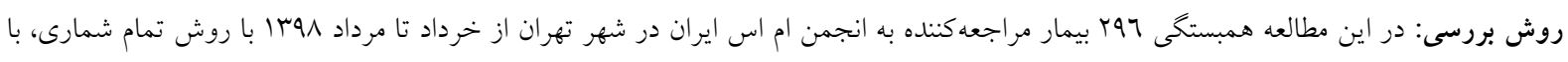

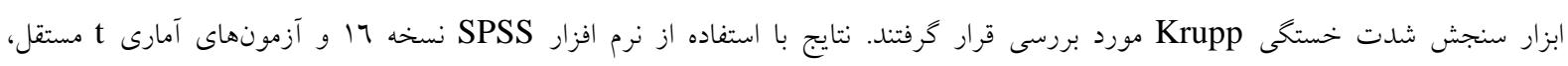
شultiple Comparisons ،ANOVA شدند. - n

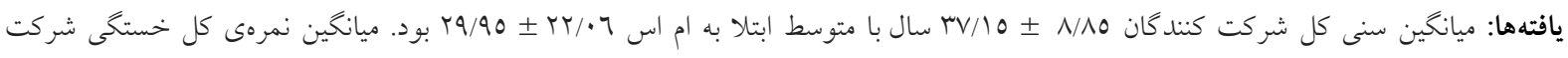

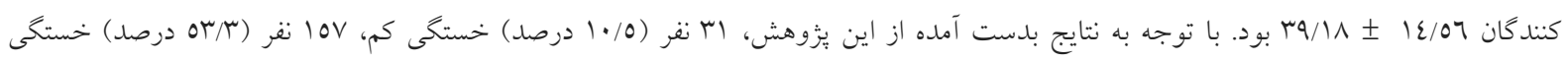

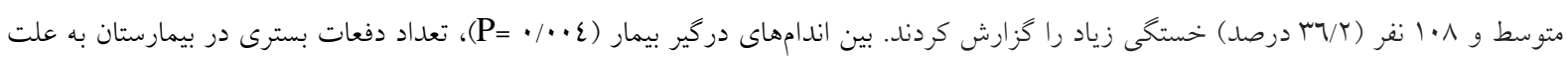

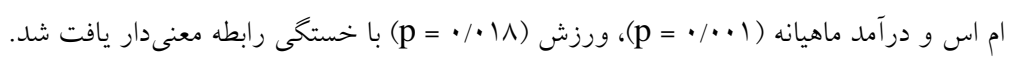

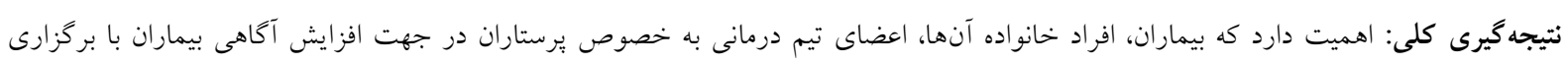

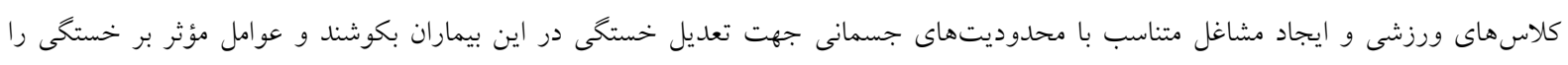

كليد وازهها: مولتيبل اكسلروزيس، خستخى، متغيرهاى جمعيت شناختى تعارض منافع: ندارد تاريخ دريافت: ع ع/2/1

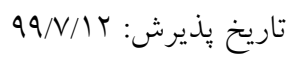

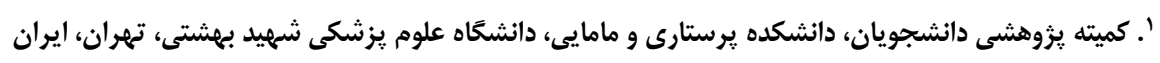

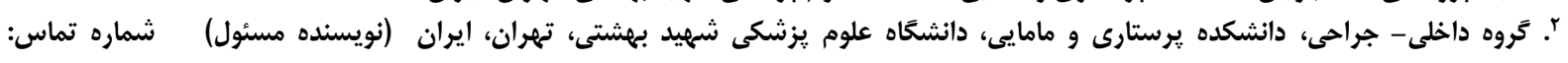
Email: Pazokian@sbmu.ac.ir .91771019re

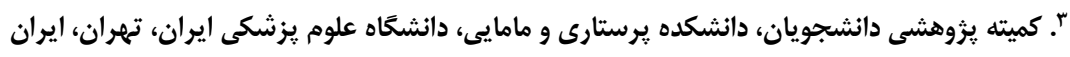


باشند (10،1). با توجه به اين كه برستاران نگاه كلنگر به

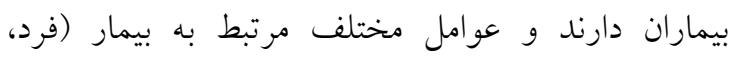

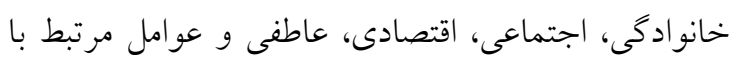

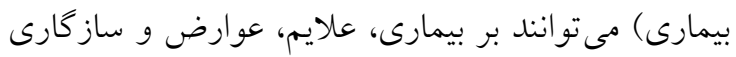

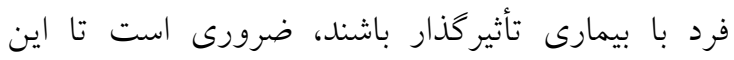
عوامل توسط برستار به خوبى شناسايى شود و تشخيص يرستارى و اقدامات لازم با توجه به اين ويزكى ها و به لهن

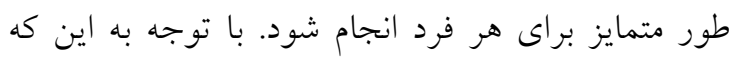

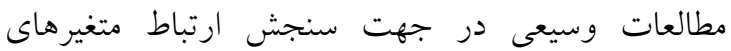
مختلف جمعيت شناختى مانند عوامل فردى (سن، جنسيت، تحصيلات و غيره)، خانوادگى (سابقه ابتلا به بيمارى در خانواده)، اجتماعى (حمايت از جانب نهادهاى

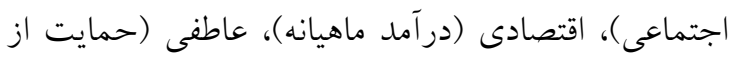
جانب خانواده) و عوامل مرتبط با بيمارى (سن شروع

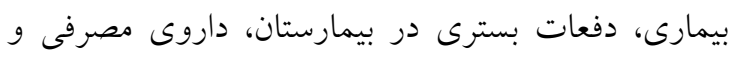

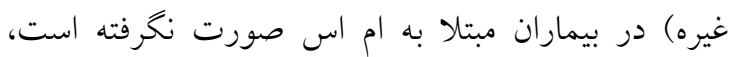

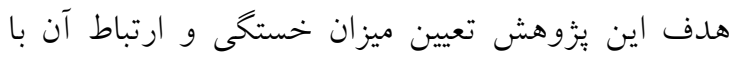

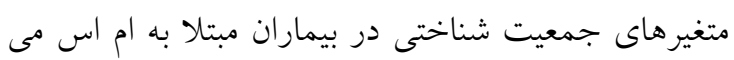

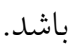

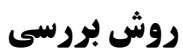

اين مطالعه توصيفى - همبستخى در فاصله بين ماههاى

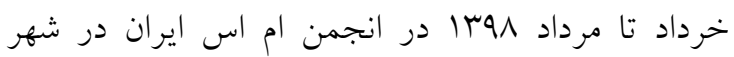
تهران انجام شد. حجم نمونه با استفاده از فرمول

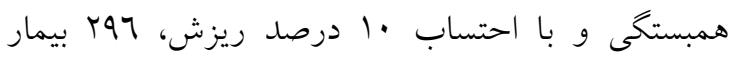
محاسبه شد. مورد ريزش نمونهها با توجه به تعداد زياد سؤالات يرسشنامه متغيرهاى جمعيت شناختى و احتمال

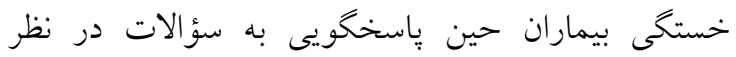

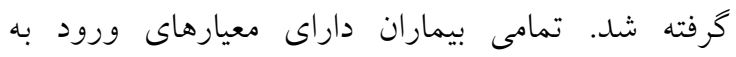
صورت تمام شمارى در مقطع زمانى وارد مطالعه شدند.

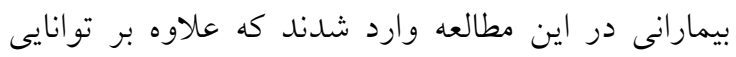

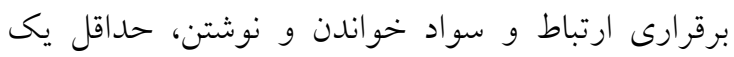
سال از ابتلاى آنها به بيمارى كذشته بود (17) و در مرحله
مقدمه

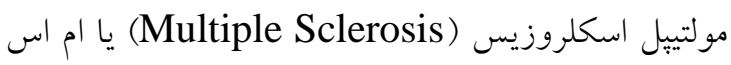
به عنوان يك بيمارى مخرب و ييشرونده سيستم (MS)

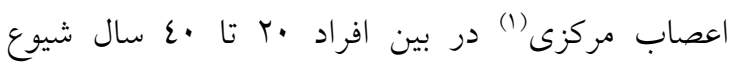
بيشترى دارد(r). شيوع ام اس در مناطق جغر افيايى و زمينه

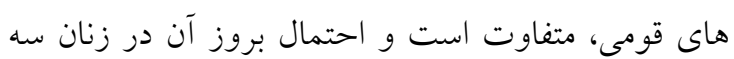
برابر مردان كزارش شده است مارت است

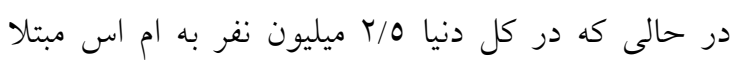

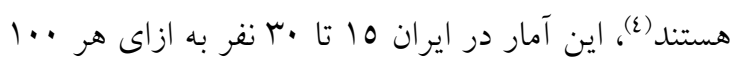

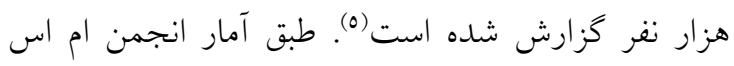

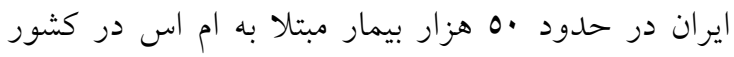

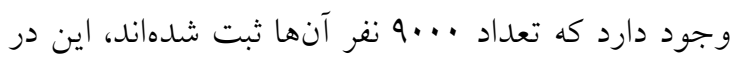
حالى است كه اين رقم در حال افزايش است (T، آن. اصفهان

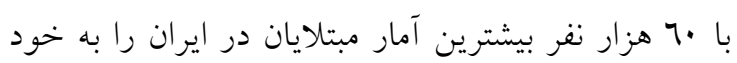
اختصاص داده است (1.9). از بين علايم مختلف تأثير كذار بر اين بيماران مانند

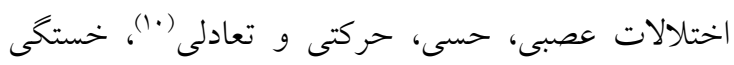

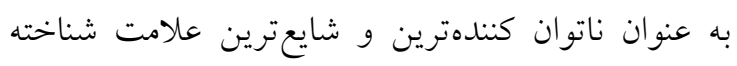

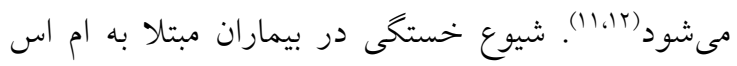
بين Vo تا •9 درصد متغير است؛ در حالى كه در ميان

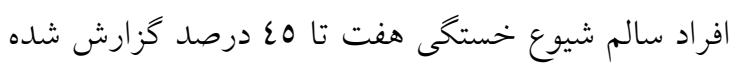
است (rاس) در مطالعهى Berger و همكاران بيان شده است كه rN/9 درصد بيماران خستخى را در طول سه سال اول تشخيص

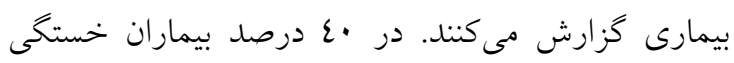

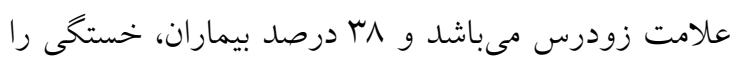
به عنوان اولين علامت تشخيصى تجربه مى كنند. همرنِين

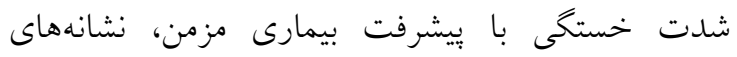

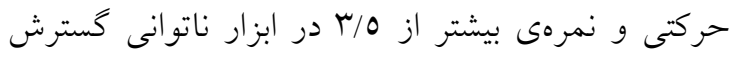

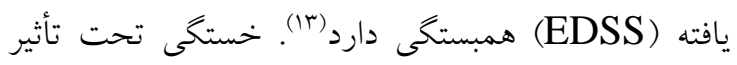
جنبههاى مختلفى از جمله وضعيت مبتلا به ام اس كاملاً

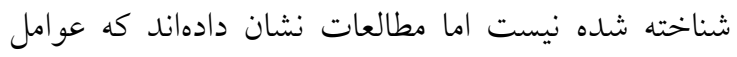
فردى مانند سن، جنسيت، نزاد و وضعيت اقتصادىاجتماعى نيز مىتوانند بر ميزان خستخى بيماران تأثير كذار 
بيانكر ميزان خستخى متوسط و نمره بالاتر از 0 ع بيانگر

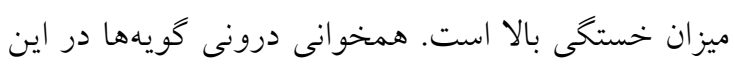

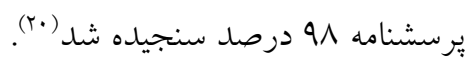
در ايران، شاهواروقى فراهانى و همكاران همخوانى

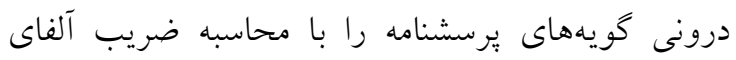

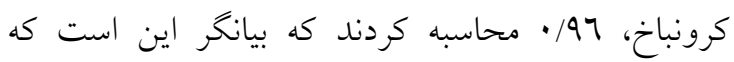

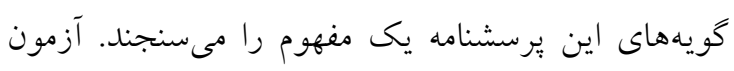

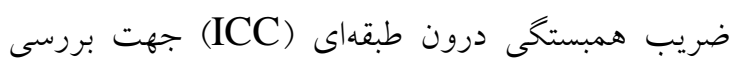

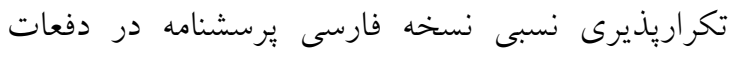

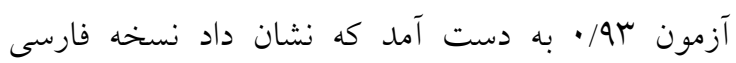
برسشنامه تكراريذيرى مناسبى داشت (II). به منظور رعايت اصول اخلاقى در يُزوهش، تمامى مراحل

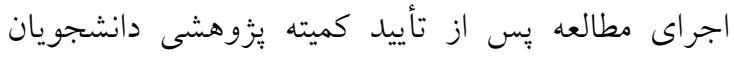

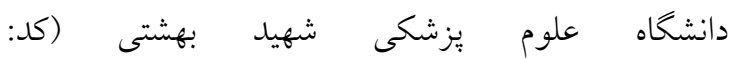
IR.SBMU.RETECH.REC.1397.928 مجوزهاى لازم و ارائه آن به مسئولين انجمن انجام شد.

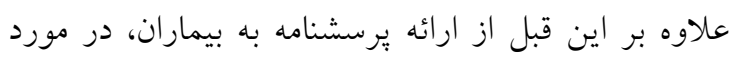

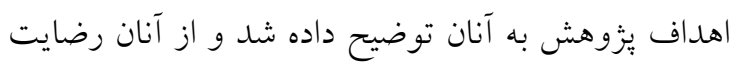
نامه كتبى اخذ شد. شركت افراد در اين يزّوهش كاملاً

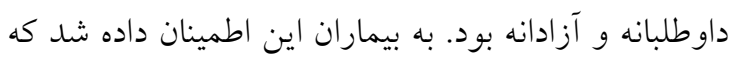

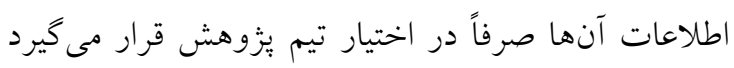

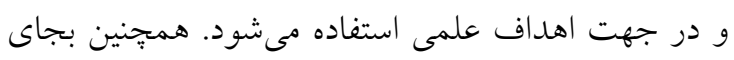

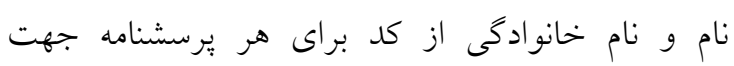
جلو كيرى از افشاى اطلاعات بيماران استفاده شد. جهت تحليل تمامى دادهها از نرم افزار آمارى نسخه 17 استفاده شد. ابتدا با خلاصه كردن نمرات هرمات هر

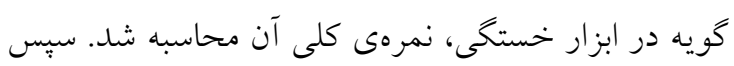

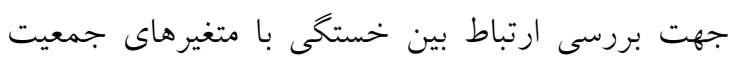

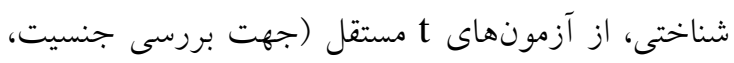

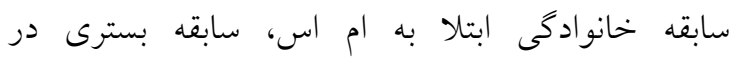

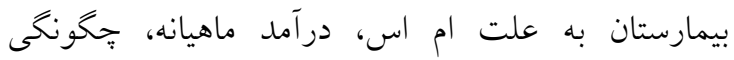

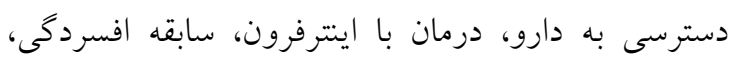

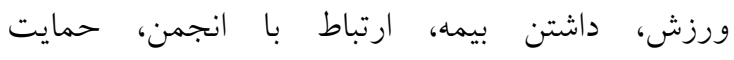

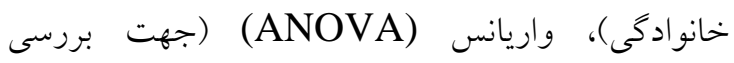

حاد بيمارى نبودند. هم:جنين نمرهى كمتر از ب/0 در ابزار ناتوانى كسترش يافته (EDSS) داشتند (17).

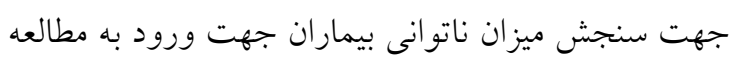

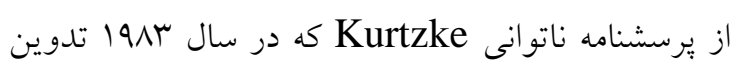

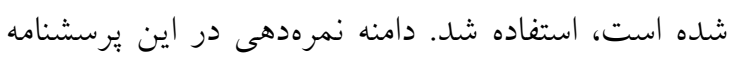

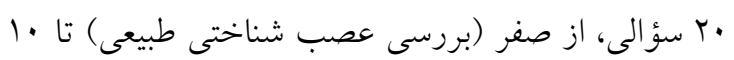

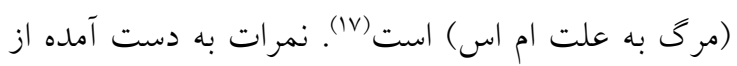

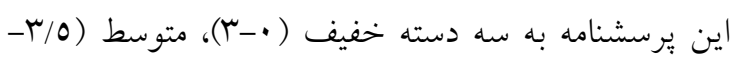

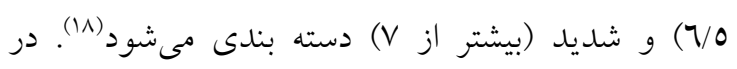

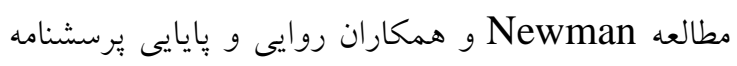

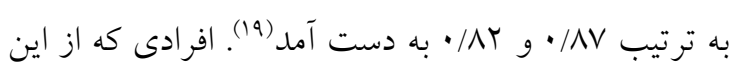
ير سشنامه نمره زير r/0 داشتند، وارد مطالعه شدند.

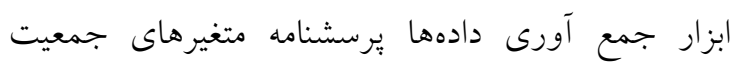
Fناختى و سنجش شدت خستخى ( Fatigue Severity Krupp (Scale: FSS

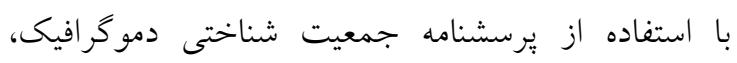

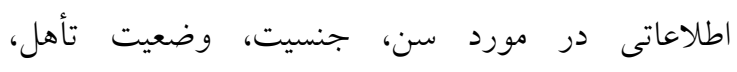

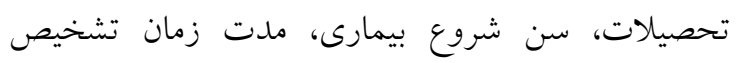

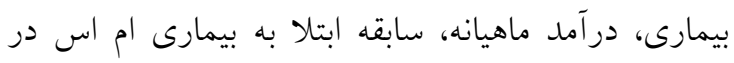

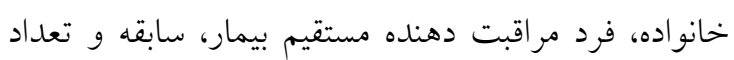

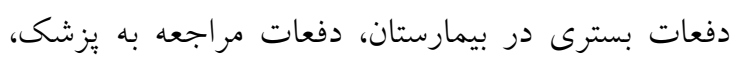

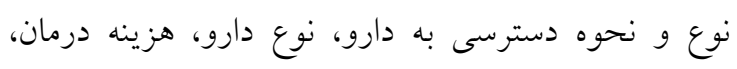

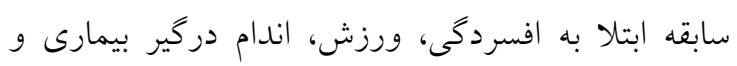

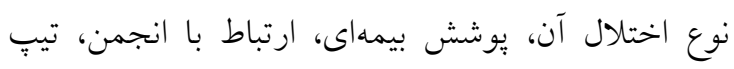

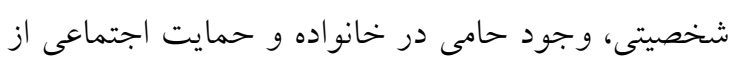

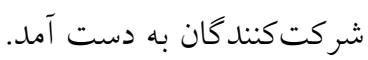
يرسشنامه سنجش شدت خستخى جهت تعيين خستكى توسط بيماران تكميل شد. اين يرسشنامه، دريافت شخصى افراد را از خستكى شان با نه

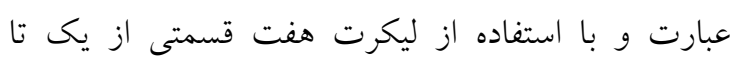

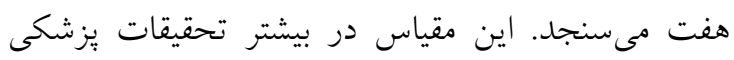
براى سنجش خستكى استفاده شده است. حداقل امتياز ممكن در اين يرسشنامه نه و حداكثر سا است. نمره بين

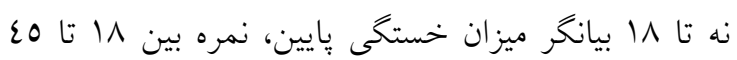




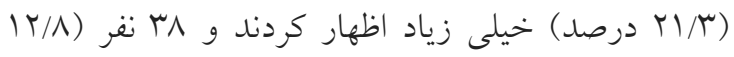
درصد) بيان كردند كه با وجود بيمه مشكلى در بيرداخت هزينهها ندارند. لازم به ذكر است ارتباط متغير هزينههاى درمانى با نوع بيمه بيماران مرتبط بوده است (9 ( • ( و بيماران با بيمه نيروهاى مسلح كمترين هزينه را براى درمان خود يرداخت مىكردند. متوسط ورزش بيماران

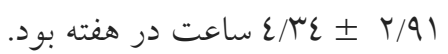

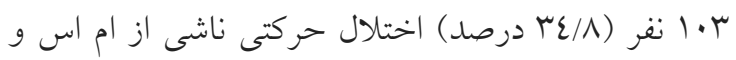
ع ا نفر (1/9) اختلال حسى ناشى از ام اس و عل نفر

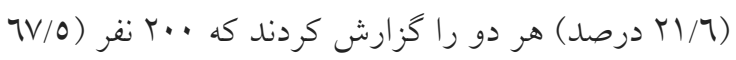
درصد) يك عضو دركير، 17 نفر (ع/0 درصد) دو عضو درگير و عع نقر (N/عا درصد) سه عضو درگير داشتند.

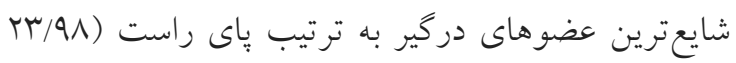
درصد از كل جمعيت)، دست راست (اس/M درصد) و و دست جֶٍ (V/TY درصد) بودهاند. بيماران از نظر دسته بندى تيب شخصيتى Rosenman and Friedman در

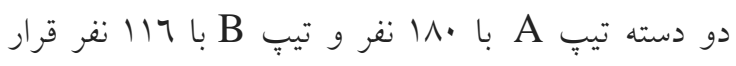
داشتند.توزيع فراوانى ديخر متغيرهاى جمعيت شناختى در جدول شماره ا بيان شده است.

وضعيت تأهل، حمايت اجتماعى، وضعيت اشتغال، مدت تشخيص بيمارى، فردى كه بيمار با او زندكى مى كند،

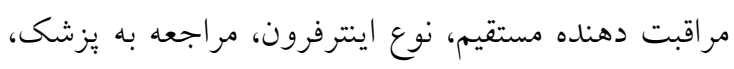

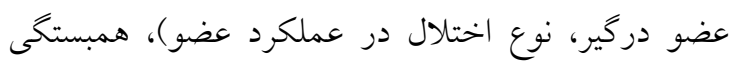
بيرسون (جهت بررسى سن بيماران) و اسبيرمن (جهت بررسى سطح تحصيلات، هزينه درمان) استفاده شد. لازم به ذكر است كه از آزمون تعقيبى يا مقايسات جند جهت تعيين مكان (Multiple Comparisons) تفاوت بين كروهها (نوع اختلال در عملكرد عضو) استفاده شد. جهت بررسى توزيع دادهها از تست بهره برده D'Agostino \& Pearson omnibus شد. P value كمتر از 0 • • به عنوان سطح قابل قبول در نظر كرفته شد.

\section{افافتهها}

در اين يزوهش بو T97 نقر شركت كردند كه ميانكين سنى كل آنها N/NO

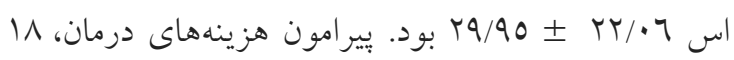

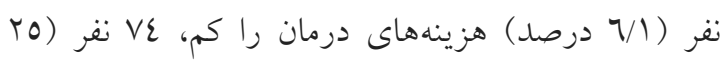

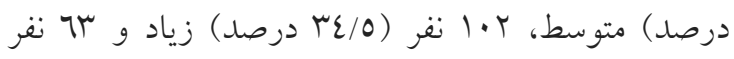
جدول شماره (: توزيع فراوانى متغيرهاى جمعيت شناختى بيماران مبتلا به مولتيبل اسكلروزيس (تعداد = جوج بيمار)

\begin{tabular}{|c|c|c|c|c|c|c|c|}
\hline درصد & تعداد & حالت & متغير & درصد & تعداد & حالت & متغير \\
\hline $1 \varepsilon / 0$ & $\varepsilon r$ & بله & سابقه خانو ادگى & $r \wedge / \varepsilon$ & $\wedge \varepsilon$ & 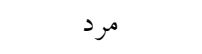 & جنسيت \\
\hline $10 / 0$ & ror & خير & & $V 1 / 7$ & rIT & زن ان & \\
\hline ro/r & vo & انجمن & & 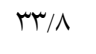 & $1 \cdots$ & مجرد & \\
\hline TO/V & $\mathrm{V} 7$ & بيمه & حمايت اجتماعى & $07 / 1$ & 177 & متأهل & وضعيت \\
\hline $\mid Y / \Lambda$ & r & هر دو & & $\mathrm{V} / \mathrm{\Lambda}$ & r & 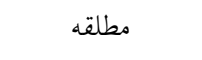 & ت تأهل \\
\hline$M / \varepsilon$ & 99 & هيج كدام & & $r / \varepsilon$ & v & همسر فوت شده & \\
\hline$r q / q$ & 111 & خانهدار & & $1 \cdot 10$ & I & زيردييلم & \\
\hline $\mid r / r$ & m & 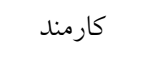 & & $\varepsilon \cdot 10$ & ir. & دييلم & سطح \\
\hline $7 / \varepsilon$ & 19 & از كار افتاده & وضعيت اشتغال & $\Lambda / \varepsilon$ & ro & فوق دييلم & تحصيلات \\
\hline $11 / 9$ & 07 & بيكار & & $r\rceil / v$ & vq & 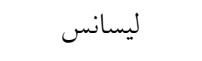 & \\
\hline $1 V / 9$ & or & شغل آزاد & & $I T / T$ & ru & ارشد & \\
\hline$\varepsilon / V$ & $1 \varepsilon$ & دانشجو & & 1 & $r$ & دكترى & \\
\hline $7 / 1$ & 11 & تنها & فردى كه بيمار با او زندگى & $\varepsilon r / q$ & ITV & يك تا ينج سال & مدت \\
\hline $9 \pi / r$ & rVI & 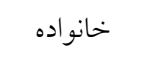 & مى كند & ro/. & $\vee \varepsilon$ & شش تا ده سال & تشخيص \\
\hline$\cdot / r$ & 1 & دوست & & $\mathrm{r} / \mathrm{A}$ & $9 \varepsilon$ & بيشتر از ده سال & \\
\hline
\end{tabular}




\begin{tabular}{|c|c|c|c|c|c|c|c|}
\hline$I V / T$ & 01 & سينوو كس & & $M r / l$ & 90 & بيمار & \\
\hline$\varepsilon / V$ & $1 \varepsilon$ & رسيزن & & $\mu / / \varepsilon$ & $9 \pi$ & همسر & مراقبت \\
\hline$\Lambda / 1$ & $r \varepsilon$ & ربيف & نوع اينترفرون & $\varepsilon / V$ & $1 \varepsilon$ & فرزند & دهنده \\
\hline $1 Y / 0$ & rV & بتافرون & & $r / \cdot$ & 9 & يدر & مستقيم \\
\hline$O / V$ & IV & آونكس & & $11 / 0$ & $r \varepsilon$ & مادر & \\
\hline$r / \cdot$ & 7 & اكتوو كس & & $|\varepsilon /|$ & $\sum r$ & بيش از دو نفر & \\
\hline $\mid r / \Lambda$ & rᄉ & بدون مشكل & & $\cdot / r$ & 1 & هر هفته & \\
\hline $7 / 1$ & 11 & كم & & $11 / 7$ & 00 & ماهيانه & مر اجعه به \\
\hline ro/. & $v \varepsilon$ & متوسط & هزينه درمان & $\mathrm{ru} / \mathrm{\Lambda}$ & 1.9 & هر سه ماه & يزشى ئ \\
\hline$r \varepsilon / 0$ & $1 \cdot r$ & زياد & & $r \cdot / 7$ & 71 & هر شش ماه & \\
\hline$r \mid r$ & r & خيلى زياد & & $19 / 9$ & 09 & در صورت نياز & \\
\hline $\mathrm{rV} / \mathrm{O}$ & 111 & به سختى & جِكَونگى دسترسى به دارو & $\Lambda Y / l$ & $r \varepsilon r$ & بله & سابقه بسترى \\
\hline $71 / 1$ & 111 & بدون مشكل & & $18 / 9$ & or & خير & \\
\hline$O T / \varepsilon$ & 100 & بله & درمان با اينترفرون & 公 & $1 \cdots$ & كافى & درآمد ماهيانه \\
\hline$\varepsilon 9 / 7$ & $1 \varepsilon V$ & خير & & $70 / 0$ & $19 \varepsilon$ & 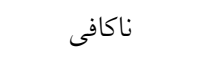 & \\
\hline $7 r / 0$ & 110 & بله & ورزش & $r_{1 / 1}$ & 94 & بله & سابقه \\
\hline$r V / r$ & 11. & خير & & $\eta / 7$ & $r \cdot r$ & خير & افسردگى \\
\hline$V \varepsilon / r$ & rr. & بله & ارتباط با انجمن & $1 \cdot / 1$ & $r$. & بله & داشتن بيمه \\
\hline ro/r & vo & خير & & $19 / \mu$ & r7o & 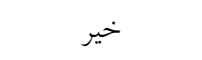 & \\
\hline$\vee q / 1$ & $r \mu \varepsilon$ & بله & حمايت خانوادگى & $\Lambda / r$ & $r \varepsilon$ & دست & \\
\hline$r \cdot / T$ & 71 & خير & & $r Y / \bullet$ & 70 & 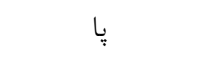 & \\
\hline$\sum 1 / q$ & $1 r \varepsilon$ & حسى & نوع اختلال در عملكرد & $V / I$ & rI & جشم & عضو درگير \\
\hline$r \varepsilon / \Lambda$ & $1 \cdot r$ & 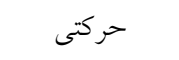 & عضو & $1 / V$ & 0 & عدم تعادل & \\
\hline \multirow[t]{3}{*}{$r \mid / 7$} & $7 \varepsilon$ & حسى - حركتى & & $\cdot / V$ & r & نخاع & \\
\hline & & & & r & $1 \cdot r$ & دو عضو & \\
\hline & & & & $11 / 0$ & $r \varepsilon$ & بيشتر از دو عضو & \\
\hline
\end{tabular}

با توجه به جدول شماره ז، بين خستخى با سن، سن شروع بيمارى، تعداد دفعات بسترى و ساعات ورزش رابطه معنىدارى يافت نشد (0) > p > (p).
ميانگين نمرهى كل خستكى شركت كنندگان 12/07 1 $9 / 1 \wedge$ بود. با توجه به نتايج به دست آمده از اين يُزوهش، اس نفر (10 1 درصد) خستخى كم، 10V نفر

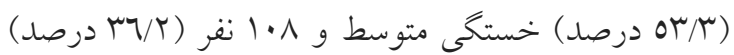

$$
\text { خستخى زياد را گزارش كردند. }
$$

جدول شماره ץ: ارتباط بين سن، سن شروع بيمارى، تعداد دفعات بسترى و ساعات ورزش با خستكى در بيماران مبتلا به مولتيبل اسكلروزيس (إنج

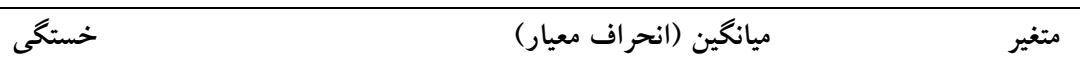

\begin{tabular}{|c|c|c|c|}
\hline P-value & ضريب همبستكى & & \\
\hline$\cdot / \mu_{0}$ &.$/ .0 \varepsilon$ & $(\Lambda / 10) r V / 10$ & سن (سال) \\
\hline D &.$/ .0 \mathrm{~V}$ & $(Y Y / \cdot T) Y q / 90$ & سن شروع بيمارى (سال) \\
\hline$\cdot / \cdots 1$ & $\cdot / r$ & $(\varepsilon / T V) \Gamma / \Lambda \Lambda$ & تعداد دفعات بسترى \\
\hline$\cdot / 29$ & $-\cdot / \cdot 0$ & $(Y / 90) \varepsilon / \varepsilon$. & ساعات ورزش \\
\hline
\end{tabular}


آن اختلال حسى - حركتى (I/N1/) و اختلال حسى (2/17) (To/77) قرار داشتند. نتيجه آزمون تعقيبى نشان داد كه

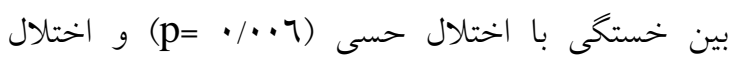

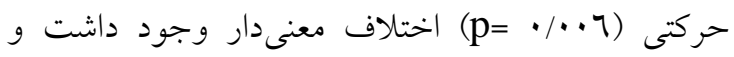
ميانگين و انحراف معيار اختلال حسى و و حركتى به لبه

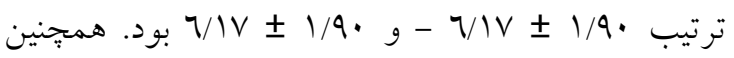

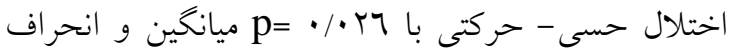

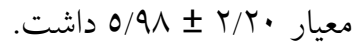

با توجه به جدول شماره سا، بين اندامهاى درگير بيمار و

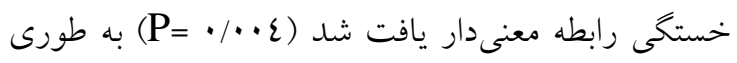

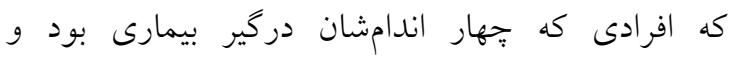
هم:جنين افرادى كه علاوه بر جهار اندام، دخهار اختلال

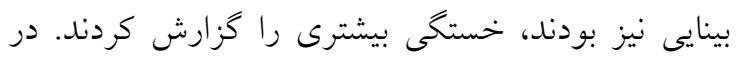

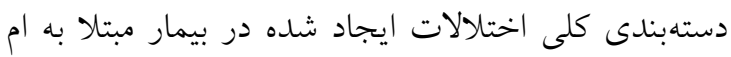

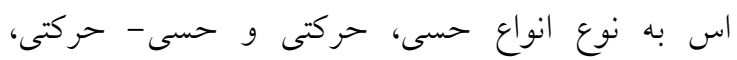
مشاهده شد كه بيشترين اختلال ايجاد شده در شركت

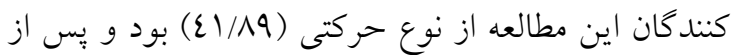

جدول شماره س: ارتباط بين خستكى و برخى متغيرهاى جمعيت شناختى در بيماران مبتلا به مولتيبل اسكلروزيس

\begin{tabular}{|c|c|c|c|c|c|c|}
\hline $\mathbf{F}$ & $\mathbf{t}$ & df & P-value & ميانخين (انحراف معيار) & حالت & متغير \\
\hline &.$- / 0 r r$ & TqE & $\cdot / 7 r$ & $(1 \varepsilon / \Gamma \varepsilon) r_{N} / q \mid$ & 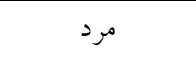 & "جنسيت \\
\hline & & & & $(10 / \cdot) r q / V \mu$ & 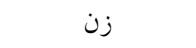 & \\
\hline \multirow[t]{4}{*}{$r / .09$} & & rq1 & $\cdot / \cdot 17$ & س & مجرد & \\
\hline & & & & $\left(\mid \varepsilon / \nearrow_{\bullet}\right) r_{N / V T}$ & متأهل & "وضعيت تأهل \\
\hline & & & & (17/・ ( ) & مطلقه & \\
\hline & & & & $(\Lambda / V I)$ or/OV & همسر فوت شده & \\
\hline \multirow[t]{3}{*}{$|/ \mu| \varepsilon$} & & $\varepsilon 9$ &.$/ 17$ & $(I r / O r) r N / \Sigma r$ & يك تا ينج سال & \\
\hline & & & & $(1 \varepsilon / 97) \Upsilon_{\Lambda} / \varepsilon \Lambda$ & شش تا ده سال & "ملت تشخيص \\
\hline & & & & $(10 / 7 r) \varepsilon \cdot / 7 r$ & بيشتر از ده سال & \\
\hline \multirow[t]{6}{*}{. TOY } & & rAT & $\cdot / 91$ & $(1 \varepsilon / 11) r q / r \wedge$ & بيمار & \\
\hline & & & & $(10 / \varepsilon r) r q / \cdot V$ & همسر & \\
\hline & & & & $(I V / 9 \Lambda) \varepsilon \cdot / 9 Y$ & فرزند & "مر اقبت دهنده مستقيم \\
\hline & & & & $(17 / 19) r \cdot 100$ & يدر & \\
\hline & & & & (Ir/2r) rq/ro & مادر & \\
\hline & & & & $(11 / V \tau) \varepsilon r / r q$ & بيش از دو نفر & \\
\hline \multirow[t]{6}{*}{ l/ArE } & & rq. &.$/ 1$ & $(1 r / q 1) r q / \cdot 1$ & خانهدار & \\
\hline & & & & $(17 / 01) r V / 9 \varepsilon$ & كارمند & \\
\hline & & & & $(1 Y / 99) \varepsilon V / \varepsilon T$ & از كار افتاده & "\#وضعيت اشتغال \\
\hline & & & & $(10 / \mu \Lambda) \varepsilon \cdot / 0 r$ & بيكار & \\
\hline & & & & r & شغل آزاد & \\
\hline & & & & $(1 r / 09) r V / 1 \varepsilon$ & دانشجو & \\
\hline \multirow[t]{5}{*}{\urcorner$/ \Sigma \wedge \Lambda$} & & TMA & $\cdot / \cdots r$ & (1r/17) ro/77 & 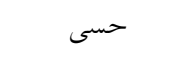 & "نوع اختلال در عملكرد \\
\hline & & & & $(1 \varepsilon / 77) \varepsilon 1 / \wedge q$ & حركتى & عضو \\
\hline & & & & $(10 / V 1) \sum 1 / V 1$ & حسى - حركتى & \\
\hline & I/VAE & TQ⿱一⿻上丨 & $\cdot / \cdot \sqrt{ } 7$ & $(10 / \varepsilon V) \varepsilon r / \Lambda r$ & بله & "سابقه بيمارى در خانواده \\
\hline & & & & $(1 \varepsilon / \Gamma T) \Gamma \wedge / O \varepsilon$ & خير & \\
\hline
\end{tabular}




\begin{tabular}{|c|c|c|c|c|c|c|}
\hline & $\cdot / \mu \cdot V$ & rq. & -/Vo9 & $\begin{array}{l}(1 \varepsilon / Y r) r q / \varepsilon 0 \\
(I \varepsilon / \Lambda r) r N / 90\end{array}$ & بدون مشكل سخت & 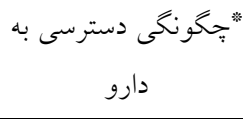 \\
\hline$\cdot / V N I$ & & $r \wedge \varepsilon$ & $.107 \varepsilon$ & $\begin{array}{l}(1 r / V 1) r q / \varepsilon q \\
(10 / \varepsilon \Lambda) r V / T V \\
(10 / r \cdot) \varepsilon \cdot / 0 r \\
(1 \varepsilon / r V) r q / \varepsilon 0\end{array}$ & 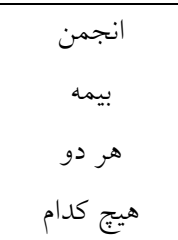 & \#مايت اجتماعى \\
\hline & $-r / r \varepsilon \varepsilon$ & rar & $\cdot / \cdot \cdot 1$ & $\begin{array}{l}(1 \varepsilon / 1 \Lambda) r 0 / \Gamma q \\
(1 \varepsilon / \Gamma r) \varepsilon 1 / / r\end{array}$ & كافى & "درآمد ماهيانه \\
\hline $1 / .17$ & & r 10 & $\cdot / \varepsilon \cdot \Lambda$ & $\begin{array}{l}(\cdot / \cdot \cdot) q / \cdot \cdot \\
(1 \varepsilon / \varepsilon \tau) r q / \varepsilon q \\
(1 \varepsilon / r \varepsilon) r N / r q \\
(1 \varepsilon / \lambda \cdot) r q / V V \\
(10 / 1 q) r q / 77\end{array}$ & 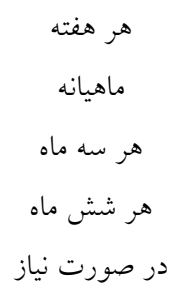 & \#مراجعه به يزشك \\
\hline & $-1 / 201$ & rar & $\cdot / 1 \varepsilon 7$ & $\begin{array}{l}(1 \varepsilon / 09) \Upsilon N / O . \\
(1 \varepsilon / Y\rceil) \varepsilon 1 / \varepsilon V\end{array}$ & خير & "حمايت خانوادكى \\
\hline & $-Y / r V T$ & TAT & $\cdot / \cdot 11$ & $\begin{array}{l}(1 \varepsilon / 07) r V / V T \\
(1 \varepsilon / T l) \varepsilon 1 / 7 q\end{array}$ & خبل & م:"وزش \\
\hline & $\cdot / \varepsilon \wedge q$ & $r q \varepsilon$ & . /7ro & $\begin{array}{l}(1 \varepsilon / 7 \varepsilon) \Gamma q / \Gamma\urcorner \\
(1 \varepsilon / r V) \Gamma \Lambda / r .\end{array}$ & خبل & "سابقه بسترى \\
\hline & - /A9T & rar & $\cdot \pi V r$ & $\begin{array}{l}(1 \varepsilon / V\urcorner) r q / 00 \\
(I r / q T) r V / N I\end{array}$ & بله & "*|رتباط با انجمن \\
\hline
\end{tabular}

دسترسى به دارو، حمايت اجتماعى، مراجعه به يزشك، حمايت خانوادگى، سابقه بسترى در بيمارستان به علت ام اس و ارتباط با انجمن رابطه معنىدارى ديله نشد (0٪

\section{بحث و نتيجه كيرى}

نتايج يُزوهش حاضر نشان داد بيشتر شركت كنندگان، ميزان متوسط خستخى را گزارش كردند. خستكى به بـ عنوان يكى از ناتوان كنندهتين و شايعترين علايم در بيماران مبتلا به ام اس شناخته مىشود كه مىتواند بر كيفيت زندگى و فعاليتهاى روزانه بيمار تأثير گذار باشد (rr). در مطالعه خدارحيمى و راستى ميزان خستخى رلى بين گروهى از مردان مبتلا به ام اس متوسط و در گروهى

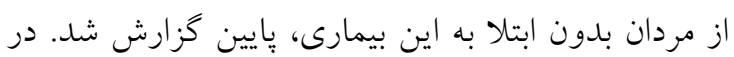
اين مطالعه همانند مطالعه حاضر شرط ورود به مطالعه،
بين تعداد دفعات بسترى در بيمارستان به علت ام اس با خستكى رابطه معنى دار يافت شد (1 ( • = كه با افزايش تعداد دفعات بسترى، بيمار خستكى بيشترى را اظهار مىداشت. بطور ميانگين افراد شركت كننده در اين مطالعه سه بار سابقه بسترى را داشتند. علاوه بر اين، درآمد ماهيانه نيز با خستخى رابطه معنىدار داشت ( ) ( $)$ بيشترى را ابراز كردند. ورزش نيز از جمله متغيرهايى بود كه در اين مطالعه مشخص شد رابطه معنىدارى با

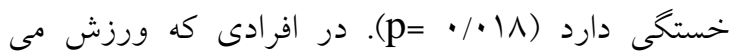
كردند، خستخى كمترى مشاهده شد. لازم به ذكر است بين خستخى با جنسيت، وضعيت تأهل، مدت نشخيص بيمارى، مراقبت دهنده مستقيم بيمار،

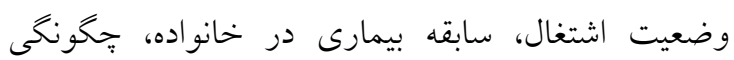


نظر مىرسد با افزايش سن و با بيشرفت بيمارى و

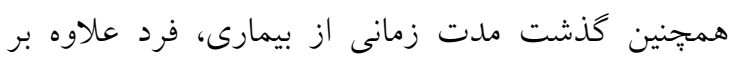

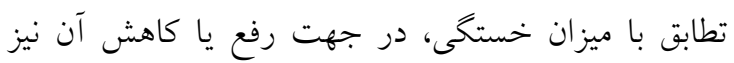

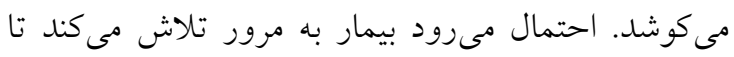
راهكارهاى مقابله با خستكى را بياموزد.

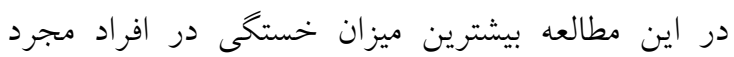
مشاهده شد. نتايج يزوهش افراسيابىفر و همكاران و رزازيان و همكاران در بيماران مبتلا به ام اس نشان داد كه وضعيت تأهل با خستخى بيماران رابطه معنى دارى ندارد

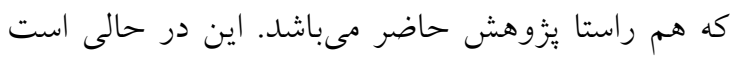
كه بيان شده است كه همسران مى توانند در سازكارى فرد با بيمارى و همجنين كاهش ناتوانى و به علاوه ييروى از درمان و بهبود وضعيت روانى بيماران نقش مهمى داشته باشند (r) در مطالعه حاضر ديده شد خستكى ارتباط معنىدارى با سطح تحصيلات در بيماران مبتلا به ام اس ندارد. افراسيابىفر و همكاران و رزازيان و همكاران در بيماران

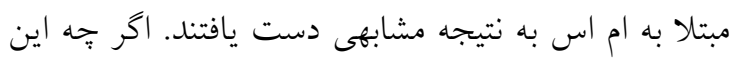

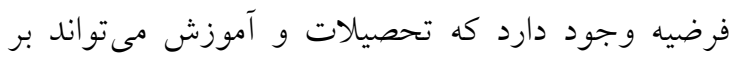

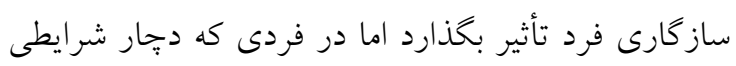
شده است كه سلامتى او را تحت تأثير قرار داده است،

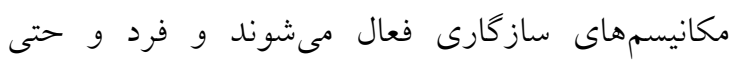
اطر افيان مى كوشند تا شرايط غير عادى را تعديل كنند. همجنين بين خستكى با وضعيت اشتغال ديده نشد. افراسيابىفر و همكاران در بيماران مبتلا به ام اس به نتايجى مشابه يزوهش حاضر دست يافتند. برخلاف

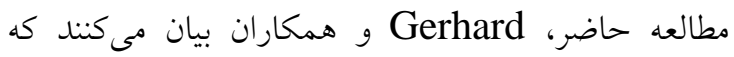
علايم خستكى در بيماران مبتلا به ام اس در افرادى كه شاغل نيستند، بيشتر ديده مىشود. به نظر مىرسد دليل

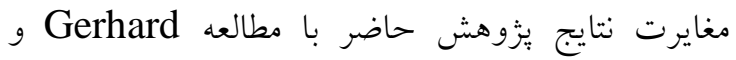
همكاران اين باشد كه در مطالعهى حاضر بيشتر شركت كنندكان در يزّوهش زن و خانهدار بودند. همانند يُزوهش حاضر، رزه و همكاران در بيماران سالمند تحت همودياليز دريافتند كه افرادى كه درآمد ماهيانه
ابتلاى بيش از يكى سال به بيمارى بود. در نتيجه بيمار در

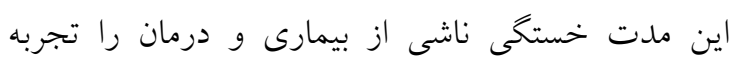
كرده و كزارش مى كند. مطالعه Berger و همكاران بر روى 17977 نفر از مرند بيماران مبتلا به ام اس نشان داد كه يك سوم اين بيماران

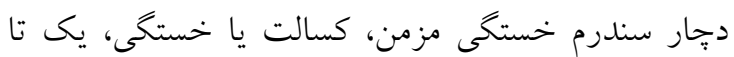
دو سال قبل از تشخيص بيمارى بودند، يك سوم از بيماران قبل از تشخيص بيمارى، هيج علامتى به جز

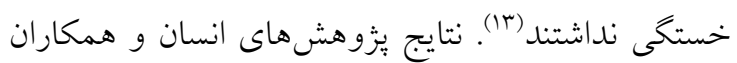
در نيشابور و همجنينين مطالعه ملكى و همكاران در اروميه نيز نتايج مشابهى داشتند (Tr.ro). از آنجايى كه هرجه ناتوانى فرد بيشتر باشد، نمره

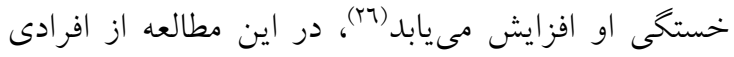

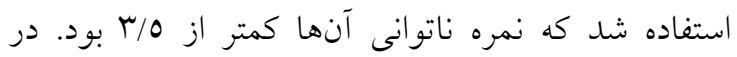

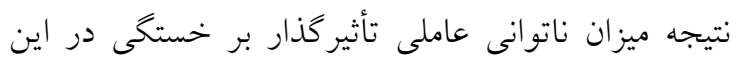

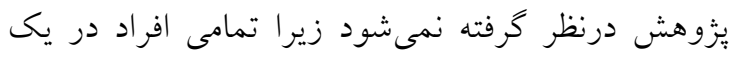

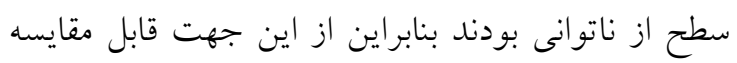

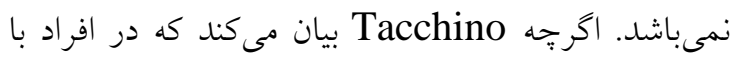

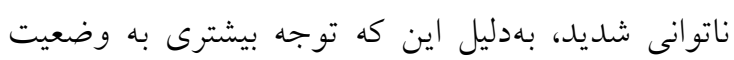

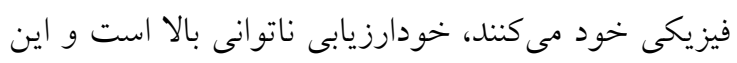

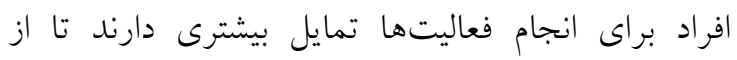
راهبردهاى خودمديريتى فعال استفاده كنند (TV). بنابراين احتمال دارد در افراد با ناتوانى بالا نيز خستخى شدئ شديد

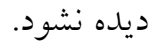
يافتهاى يزوهش نشان داد كه رابطه معنىدارى بين جنسيت و سن با خستخى وجود ندارد. نتايج مطالعه Yيز مشابه يزوهش حاضر است و و و و ارتباطى بين سن و جنسيت با خستخى نيافتند. برخلاف وهن نتايج يزوهش حاضر، مطهرىنزاد و همكاران در سمنان بيان مى كند كه با افزايش سن، خستخى بيشتر مىشود و

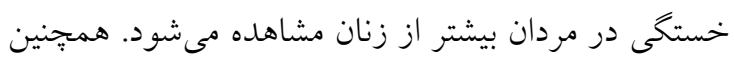
با افزوده شدن يكى سال به سن فرد در مردان، بر شدت

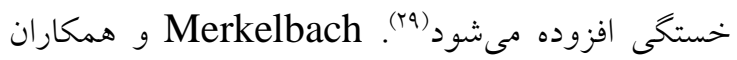
در آلمان همبستخى قوى بين خستخى و سن دريافتند. به 


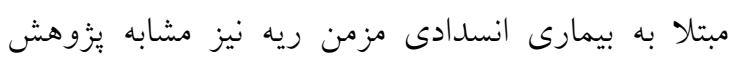

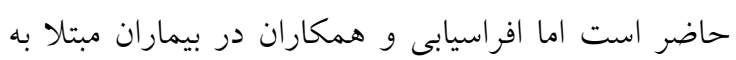

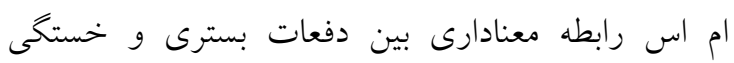

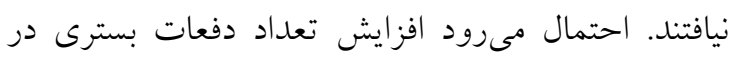

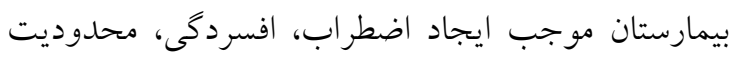

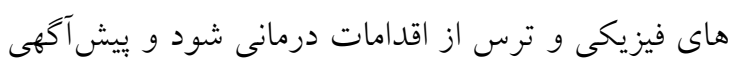

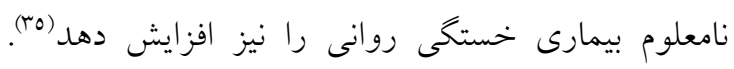

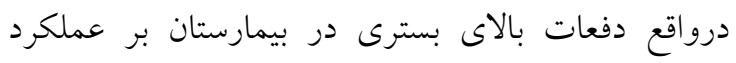

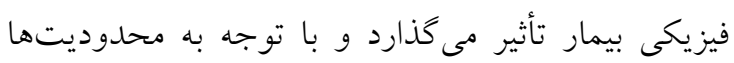
فرد خستخى بيشترى را تجربه مى كند. در مطالعه حاضر، ارتباطى بين داروى مصرفى بيمار با درديا خستخى مشاهده نشد. Flachenecker و همكاران بيان مى كند كه در بيماران مبتلا به ام اس ارتباط معنى دارى بين

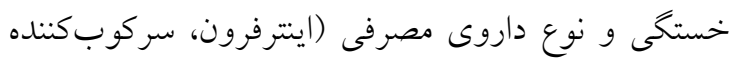

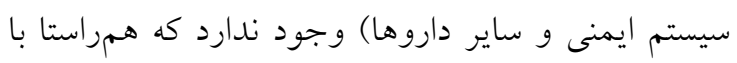
يزّوهش حاضر است ولى در مطالعه رزازيان و همكاران

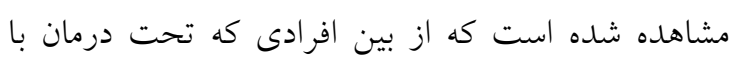

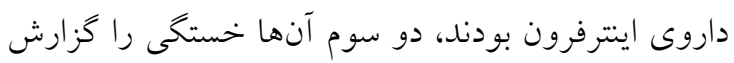

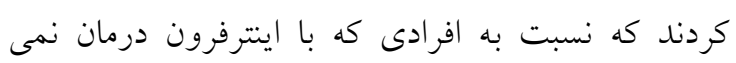
شدند، تفاوت معنى دار داشت.

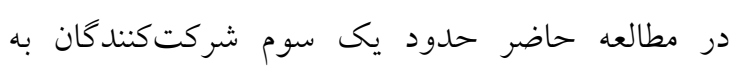

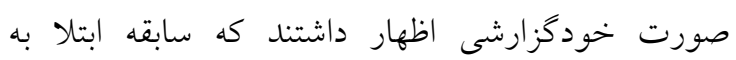

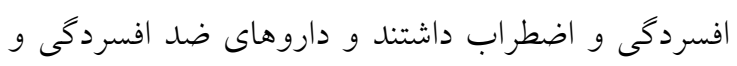

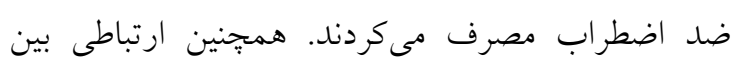

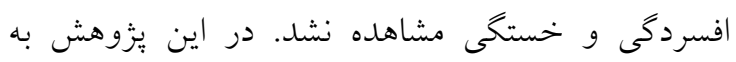
دليل ماهيت خودگزارشى توسط بيمار، تنها به اظهار بيمار

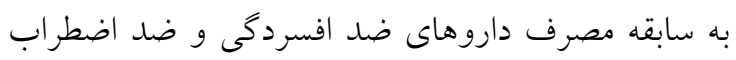

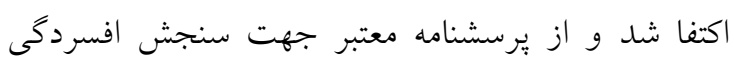

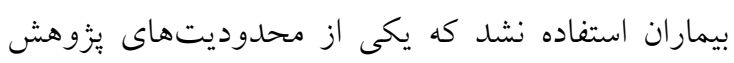

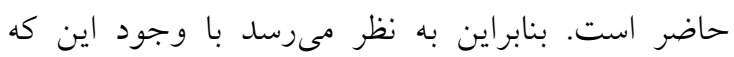

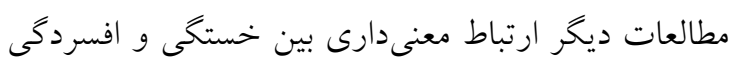

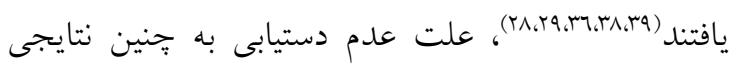
در مطالعه حاضر همين امر باشد.
كافى و بيمه دارند، خستكى كمترى را بروز مىدهند (rr).

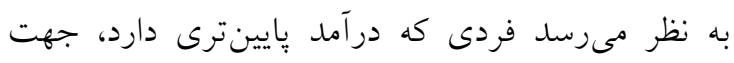

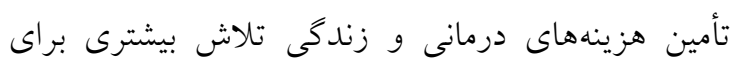

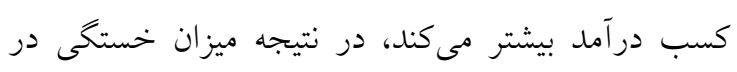

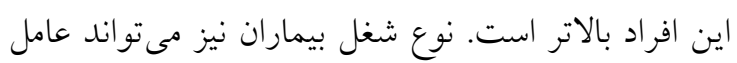

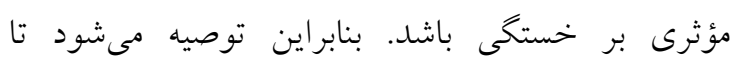
مطالعاتى در مورد شناسايى ارتباط بين نوع شغل بيماران

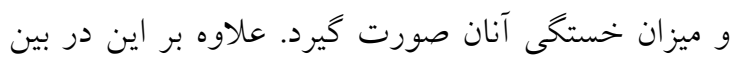

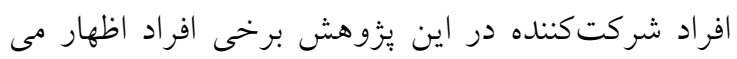

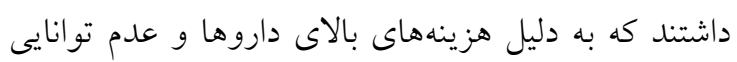

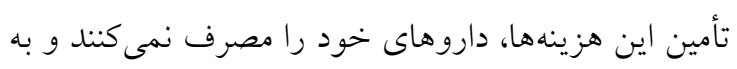

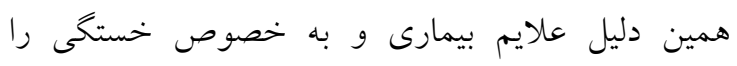
شديدتر احساس مى كنند. بنابراين به نظر مىرسد در درآمد بهد

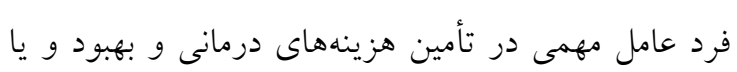
تشديد علايم است. در مطالعه حاضر ارتباط معنى دارى بين سن شروع بيمارى و مدت تشخيص بيمارى با خستخى ديلده نشد. اين نتايج

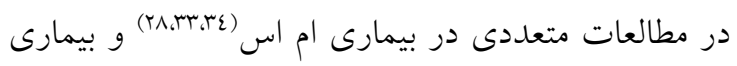

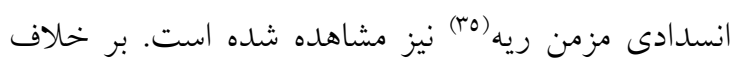

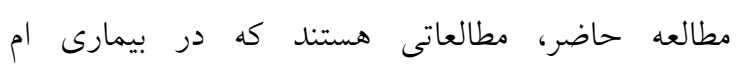

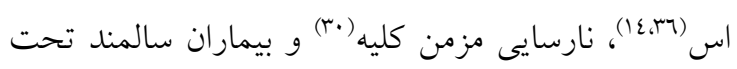

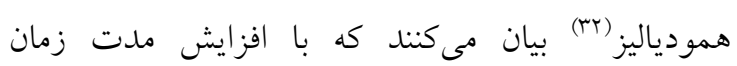
بيمارى، خستخى بيشتر مى شود.

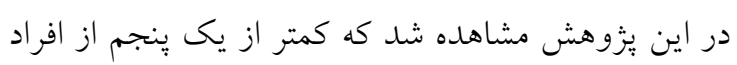

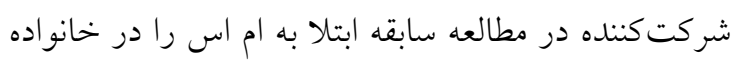

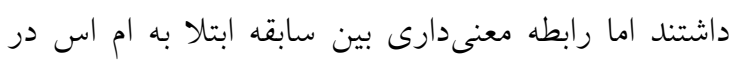

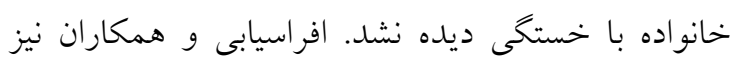

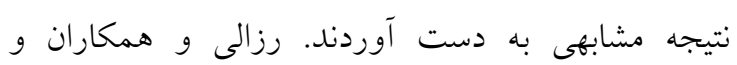

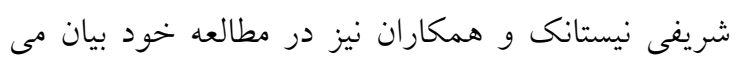

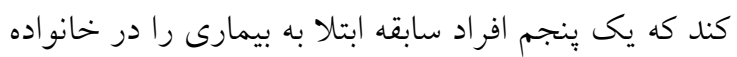
داشتهاند. در مطالعه حاضر مشخص شد در افرادى كه تعداد دفعات بيشترى در بيمارستان بسترى شدهاند، خستكى بيشترى

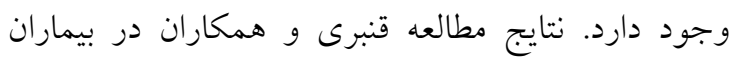


در مطالعه حاضر ارتباط معنىدارى بين حمايت از طرف

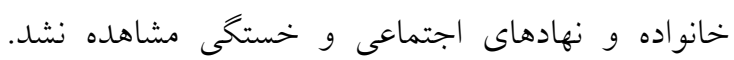

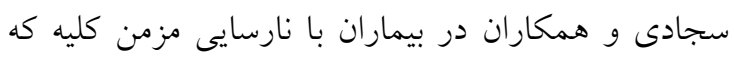
تحت همودياليز هستند، نيز نتيجه مشابهى به دست

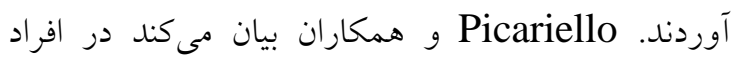
مبتلا به بيمارىهاى كليوى به عنوان بيمارى مزمن، كه خستخى شديدى را تجربه مى كنند، حمايت اجتماعى و حتى حمايت از جانب خانو اده خود را نيز درى نمى كنند. همجنين افرادى كه خستى بيشترى را تجربه مى كند و بيشتر از سايرين احساس تنهايى مىكنند، توانايى خودمراقبتى بايين ترى دارند. از طرفى رزه و همكاران در بيماران سالمند تحت همودياليزى دريافتند كه بين حضور همسر به عنوان حامى و خستخى رابطه معنىدار وجود دارد. همجنين بيان مى كند كه وجود حامى مىتواند در كاهش ناتوانى و تنش، بهبود وضعيت روانى بيمار،

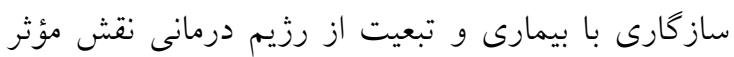

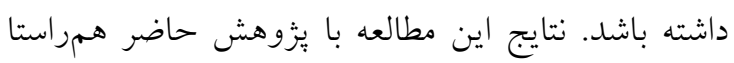

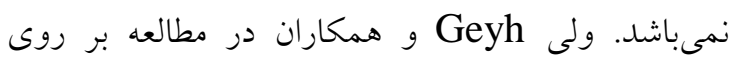
بيماران مبتلا به آسيبهاى طناب نخاعى بيان مىكند كه ونه

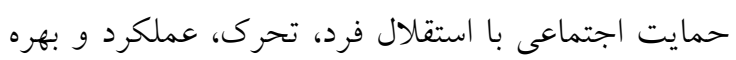
ورى ارتباط دارد. اين مطالعه حمايت اجتماعى را عامل محيطى مهم و تأثير گذار بر عملكرد و سلامتى مى مداند.

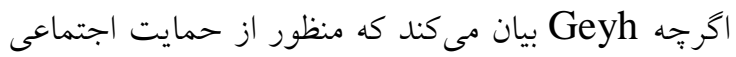
در اين مطالعه حمايت در قالب حمايت عاطفى، مراقتى

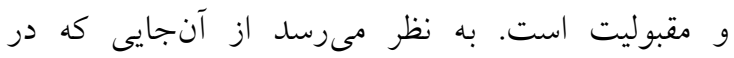
يُزوهش حاضر افراد با ناتوانى كمتر از ب/0 شركت داشتند و اين افراد از نظر فيزيكى كاملاً مستقل بودند و وحتى حتى إنى بدون وسايل كمكحركتى راه مىرفتند، از اين نظر نيازى به كمك از جانب نزديكان خود نداشتند، به همين دليل احتمال مىرود حمايت از جانب ديگران در فرد مستقل بهل

در ميزان خستخى نقشى نداشته باشد.

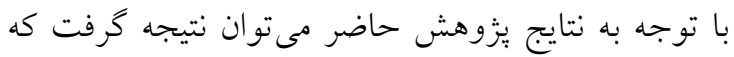

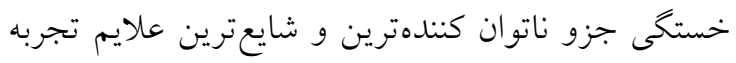
شده توسط بيماران مبتلا به ام اس است. اهميت دارد كه تئن
بيش از نيمى از شركتكنندكان در اين يزوهش ورزش

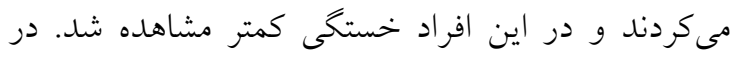
مطالعه سجادى و همكاران در بيماران مبتلا به نارسايى

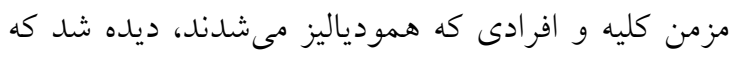

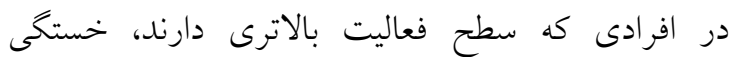

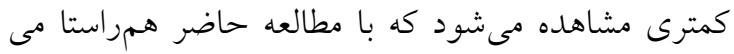
باشد. در مطالعهاى نغارش و همكاران تأثير ورزش كوتاه

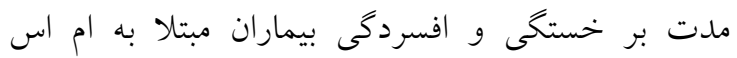

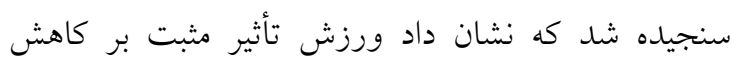

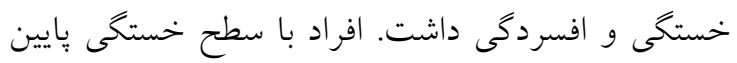
و متوسط، به احتمال زياد ناتوانى كمترى از نظر جسمى داسي

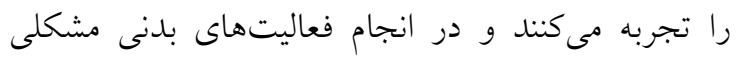

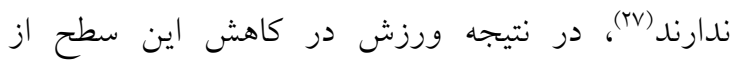
خستى تأثير گذار است. همجنين در افراد با نمر ات بالاتر خستخى، وضعيت عملكردى فرد و درى عمومى از

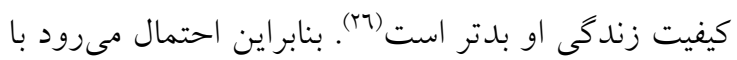

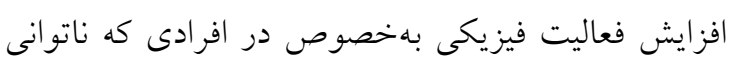
كمترى دارند، خستخى كمترى در فرد ايجاد شود. در مطالعه حاضر بيشتر شركت كنندگان بيشترين شكايت را از اختلالات حسى - حركتى داشتند. بيامنى و ميرى نيز

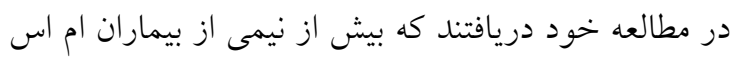

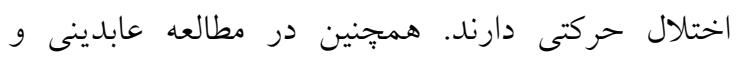
همكاران و رزالى و همكاران بيشترين شكايت بيماران از

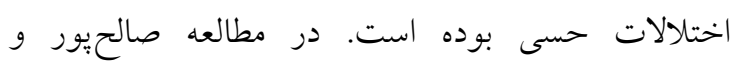

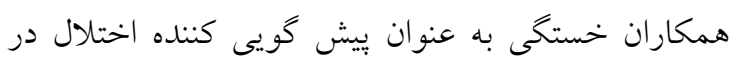

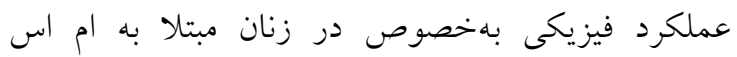
معرفى شده است. همجنين خستكى در افراد با مشكلات

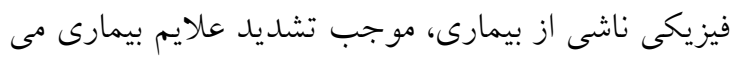

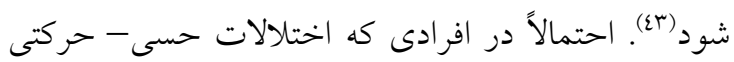
دارند به دنبال كاهش فعاليتهاى فيزيكى، خستخى

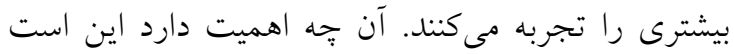

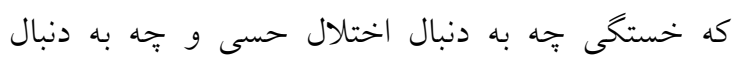
اختلال حركتى در بيمار ايجاد شده باشد، بايد مدنظر يرستاران قرار گرفته و در جهت رفع آن تلاش شود. 


$$
\begin{aligned}
& \text { در آينده يزوهشهايى در جهت تعيين مشاغل مناسب با }
\end{aligned}
$$

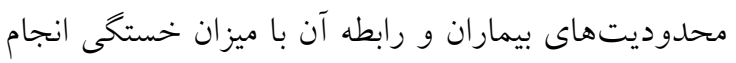

$$
\begin{aligned}
& \text { شود تا كمك بيشترى به اين بيماران شود. } \\
& \text { تعارض منافع: هيج گونه تعارض منافع توسط نويسندگان }
\end{aligned}
$$

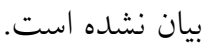

$$
\begin{aligned}
& \text { تقدير و تشكر } \\
& \text { اين مقاله حاصل طرح مصوب شوراى ئزوهشى كميته }
\end{aligned}
$$

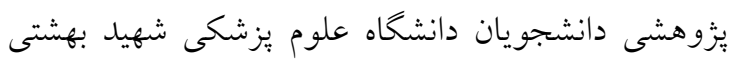

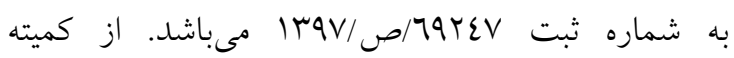

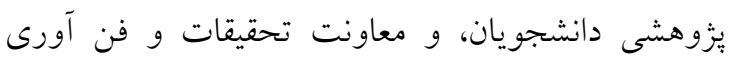

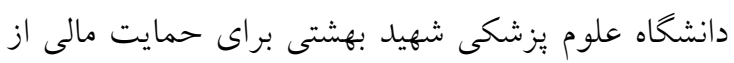

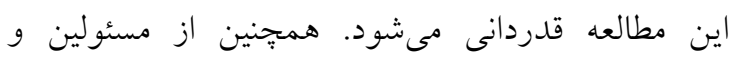

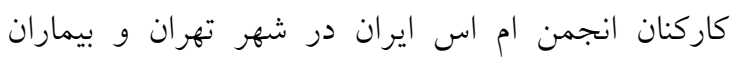

$$
\begin{aligned}
& \text { محترم شركت كننده در مطالعه تشكر و قدردانى مىشود. }
\end{aligned}
$$

\section{References}

1. Fernández-Muñoz JJ, Cigarán-Méndez M, Navarro-Pardo E, Pérez-de-Heredia-Torres M, ParásBravo P, Fernández-de-las-Peñas $\mathrm{C}$. Is the association between health-related quality of life and fatigue mediated by depression in patients with multiple sclerosis? A Spanish cross-sectional study. BMJ open. 2018;8(1):1-7.

2. Safari M, Gholamzadeh A, Asadi A, Mahjour M. The therapeutic and anti-inflammatory effects of ginseng in multiple sclerosis patients. Razi Journal of Medical Sciences. 2020;27(2):59-69. [Persian]

3. Daneshjoo A, Gheitasi M, Jaffari N. The effect of six weeks' massage in water on walking speed, postural control, pain intensity, fatigue and quality of life in women with multiple sclerosis. Anesthesiology and Pain. 2020;11(1):70-84. [Persian]

4. Jalili N, Poursafa A, Khazaali K, Rostami H, Jamshidian E, Mohammadi Z, Kamali F, Bahrani N. Investigating Environmental Barriers Affecting Participation in Patient With Multiple Sclerosis. Archives of Rehabilitation. 2020;21(1):2-21. [Persian]

5. Shahnazari Z, Marandi SM, Shayegan Nejad V. The effect of pilates exercises and aquatic trainning on walking speed in women with multiple sclerosis. Journal of Research Development in Nursing and Midwifery. 2013;10(2):10-7. [Persian]

6. Ghadampour E, Radmehr P, Yousefvand L. The effectiveness of acceptance and commitment based treatment on social competence and life expectancy of patients with multiple sclerosis. Armaghane danesh. 2017;21(11):1100-14. [Persian]

7. Payamani F, Cheraghi F, Borzou SR, Hojjatoleslami S, Khatiban M. Nursing process based on Johnson's Behavioral System Model in Patients with Multiple Sclerosis: Case Report. Journal of Nursing Education (JNE). 2020;9(2):19-26. [Persian]

8. Asgharkhah E, Shareh H. Effectiveness of group metacognitive therapy in self-efficacy and defense styles in women with multiple sclerb̆sis. Journal of Fundamentals of Mental Health. 2017;19(4):330-40. [Persian] 
9. Dalvi-Isfahani F, Alimohammadi N, Pahlavanzadeh S. The Effectiveness of Group Psychological Training on the Depression of family caregivers Multiple Sclerosis Patients: Clinical Trials. Journal of Research in Behavioural Sciences. 2020;18(1):91-100. [Persian]

10. Brownlee WJ, Hardy TA, Fazekas F, Miller DH. Diagnosis of multiple sclerosis: progress and challenges. The Lancet. 2017;389(10076):1336-46.

11. Blikman LJ, van Meeteren J, Twisk JW, de Laat FA, de Groot V, Beckerman H, Stam HJ, Bussmann JB, Trefams-Ace study group. Effectiveness of energy conservation management on fatigue and participation in multiple sclerosis: A randomized controlled trial. Mult Scler J. 2017;23(11):1527-41.

12. Pazokian M, Shanan M, Zakerimoghadam M, Mehran A, Yekefallah L. The Comparative Effects of Stretching with Aerobic and Aerobic Exercises on Fatigue in Multiple Sclerosis Patients: A Randomized Controlled Clinical Trial. International Journal of Community Based Nursing and Midwifery. 2013;1(4):230-7. [Persian]

13. Berger JR, Pocoski J, Preblick R, Boklage S. Fatigue heralding multiple sclerosis. Mult Scler J. 2013;19(11):1526-32.

14. Razazian N, Shokrian N, Bostani A, Moradian N, Tahmasebi S. Study of fatigue frequency and its association with sociodemographic and clinical variables in patients with multiple sclerosis. Neurosciences. 2014;19(1):38-42.

15. Abedini M, Paksersht M, Rafiei A, Valadan R, Amjadi O, Khajavi R, Abediankenari S, Habibi R. Demographic and clinical characteristics of multiple sclerosis. Journal of Mazandaran University of Medical Sciences. 2016;25(132):13-22. [Persian]

16. Fragoso YD, Silva ÉO, Finkelsztejn A. Correlation between fatigue and self-esteem in patients with multiple sclerosis. Arquivos de neuro-psiquiatria. 2009;67(3B):818-21.

17. Kurtzke JF. Rating neurologic impairment in multiple sclerosis: an expanded disability status scale (EDSS). Neurology. 1983;33(11):1444-52.

18. Sangelaji B, Salimi Y, Dastoorpour M, Mansouri T, Ashrafinia F, Esmaeilzadeh N, Asadi-Lari M. The relationship between disability and quality of life in multiple sclerosis patients. Health and Development Journal. 2013;2(3):203-13. [Persian]

19. Newman MA, Dawes H, Van den Berg M, Wade DT, Burridge J, Izadi H. Can aerobic treadmill training reduce the effort of walking and fatigue in people with multiple sclerosis: a pilot study. Mult Scler J. 2007;13(1):113-9.

20. Krupp LB, LaRocca NG, Muir-Nash J, Steinberg AD. The fatigue severity scale: application to patients with multiple sclerosis and systemic lupus erythematosus. Archives of neurology. 1989;46(10):1121-3.

21. Shahvaroughi-Farahani A, Azimian M, Falahpour M, Karimlou M. Reliability of the Persian version of the Fatigue Assay Scale in Multiple Sclerosis Patients. Quarterly Journal of Rehabilitation Research. 2009;10(4):46-51. [Persian]

22. Bisecco A, Caiazzo G, d'Ambrosio A, Sacco R, Bonavita S, Docimo R, Cirillo M, Pagani E, Filippi M, Esposito F, Tedeschi G. Fatigue in multiple sclerosis: The contribution of occult white matter damage. Mult Scler J. 2016;22(13):1676-84.

23. Khodarahimi S, Rasti A. The roles of fatigue, depression, and Big Five Personality traits in males with and without multiple sclerosis disease. Clínica y salud. 2015;26(2):91-6.

24. Ensan N, Boogar IR, Talepasand S, Estilaee F. The effectiveness of mindfulness-based stress reduction in fatigue severity among patients with multiple sclerosis. Studies in Medical Sciences. 2020;31(2):137-45. [Persian]

25. Maleki FS, Khalkhali HR, Hemmati Maslak Pak M. Study The Effect Of Performance Roy Adaptation Model On Intensity And Effects Of Fatigue In Multiple Sclerosis Patients. The $J$ Urmia Nurs Midwifery Fac. 2016;14(6):571-9. [Persian]

26. Fernández-Muñoz JJ, Morón-Verdasco A, Cigarán-Méndez M, Muñoz-Hellín E, Pérez-de-Heredia-Torres M, Fernández-de-Las-Peñas C. Disability, quality of life, personality, cognitive and psychological variables associated with fatigue in patients with multiple sclerosis. Acta Neurol Scand. 2015;132(2):118-24.

27. Tacchino A, Brichetto G, Zaratin P, Battaglia MA, Ponzio M. Self-assessment reliability in multiple sclerosis: the role of socio-demographic, clinical, and quality of life aspects. Neurol Sci. 2019;40(3):617-20. 
28. Mills RJ, Young CA. The relationship between fatigue and other clinical features of multiple sclerosis. Mult Scler J. 2011;17(5):604-12.

29. Motaharinezhad F, Parvaneh S, Bakhtiary AH, Alizadeh N, Ghahari S. The effect of mood and cognition on relationship between sleep disturbances and fatigue in people with multiple sclerosis. Koomesh. 2016 19:613-9. [Persian]

30. Sajjadi A, Farmahini Farahani B, Esmailpoor Zanjani S, Dormanesh B, Zare MO. Effective factors on fatigue in patients with chronic renal failure undergoing hemodialysis. J Crit Care Nurs. 2010;3(1):33-8.

31. Gerhard L, Dorstyn DS, Murphy G, Roberts RM. Neurological, physical and sociodemographic correlates of employment in multiple sclerosis: A meta-analysis. $J$ Health Psychol. 2020;25(1):92-104.

32. Rejeh N, Hearavi-Karimoo M, Bahrami T, Raeesi R, Tadrisi SD. The assessment of factors affecting fatigue in older people with hemodialysis. Iranian Journal of Nursing Research. 2015;10(3):108-17. [Persian]

33. Afrasiabifar A, Mehri Z, Sadat SJ, Shirazi HR. The effect of Orem's self-care model on fatigue in patients with multiple sclerosis: A single blind randomized clinical trial study. Iranian Red Crescent Medical Journal. 2016;18(8). [Persian]

34. Lerdal A, Celius EG, Moum T. Fatigue and its association with sociodemographic variables among multiple sclerosis patients. Mult Scler J. 2003;9(5):509-14.

35. Ghanbari A, Shirmohamadi N, Paryad E, Kazemnejad LE. Predictors of fatigue in patients with chronic obstructive pulmonary disease. Journal of Knowledge \& Health 2016;11(3):25-31. [Persian]

36. Merkelbach S, Schulz H, Kölmel HW, Gora G, Klingelhöfer J, Dachsel R, Hoffmann F, Polzer U. Fatigue, sleepiness, and physical activity in patients with multiple sclerosis. J Neurol. 2011;258(1):74-9.

37. Neyestanak S, Heydari M, Hoseini AF, Ghodusi Borujeni M, Seyedfatemi N. Self esteem and its associated factors in patients with multiple sclerosis. Iran Journal of Nursing. 2012;25(78):1422. [Persian]

38. Flachenecker P, Kümpfel T, Kallmann B, Gottschalk M, Grauer O, Rieckmann P, Trenkwalder C, Toyka KV. Fatigue in multiple sclerosis: a comparison of different rating scales and correlation to clinical parameters. Mult Scler J. 2002;8(6):523-6.

39. lriarte J, Subirá ML, de Castro P. Modalities of fatigue in multiple sclerosis: correlation with clinical and biological factors. Mult Scler J. 2000;6(2):124-30.

40. Negaresh R, Motl R, Mokhtarzade M, Ranjbar R, Majdinasab N, Khodadoost M, Zimmer P, Baker JS, Patel D. Effect of short-term interval exercise training on fatigue, depression, and fitness in normal weight vs. overweight person with multiple sclerosis. Explore. 2019;15(2):13441.

41. Payamani F, Miri M. Survey of symptoms and side effects in patients with multiple sclerosis. Journal of Research Analysis of Nursing Aligoodarz: Mndysh. 2011;2(2):3. [Persian]

42. Rezaali S, Khalilnezhad A, Moghadasi AN, Chaibakhsh S, Sahraian MA. Epidemiology of multiple sclerosis in Qom: Demographic study in Iran. Iranian journal of neurology. 2013;12(4):136. [Persian]

43. Salehpoor G, Kafi S, Rezaei S, Hosseininezhad M. The Investigation Relationship among Physical Functioning Impairment with Fatigue, Psychological Symptoms and Body Mass Index in Women with Multiple Sclerosis. Research of Behavioral Sciences. 2014;11(6):641-56. [Persian]

44. Geyh S, Nick E, Stirnimann D, Ehrat S, Michel F, Peter C, Lude P. Self-efficacy and self-esteem as predictors of participation in spinal cord injury-an ICF-based study. Spinal Cord. 2012;50(9):699-706. 